\title{
MK-801 Prevents Alterations in the Mesoaccumbens Dopamine System Associated with Behavioral Sensitization to Amphetamine
}

\author{
Marina E. Wolf, Francis J. White, and Xiu-Ti Hu \\ Department of Neuroscience, University of Health Sciences/The Chicago Medical School, North Chicago, Illinois \\ 60064-3095
}

Behavioral sensitization to psychomotor stimulants has been shown to be accompanied by a number of alterations in the mesoaccumbens dopamine (DA) system, including DA autoreceptor subsensitivity in the ventral tegmental area (VTA), postsynaptic $D_{1}$ receptor supersensitivity in the nucleus accumbens (NAC), and augmentation of the DA-releasing effects of stimulants in the NAc. The present study examined whether coadministration of the noncompetitive NMDA antagonist MK-801 with amphetamine, which has been shown to prevent the development of behavioral sensitization to amphetamine, would also prevent these changes in mesoaccumbens DA function. Rats were treated for $5 \mathrm{~d}$ with amphetamine according to a regimen known to produce lasting sensitization. Extracellular single-unit recordings from VTA DA neurons in amphetamine-treated rats, performed after $1 \mathrm{~d}$ of abstinence, revealed robust autoreceptor subsensitivity to DA agonists. This was prevented in rats coadministered MK-801 with amphetamine during the 5 d pretreatment period. Recordings from NAC neurons in amphetamine-treated rats demonstrated supersensitivity of $D_{1}$ receptors to iontophoretic administration of selective agonists when tested after $7 \mathrm{~d}$ of abstinence. This was also prevented by MK-801 coadministration. Microdialysis studies performed in awake rats after $7 \mathrm{~d}$ of abstinence failed to demonstrate augmentation of amphetamine-stimulated DA release in amphetamine-treated rats as compared to water controls, despite the fact that behavioral sensitization was evident in the former group during microdialysis experiments. MK-801 coadministration prevented behavioral sensitization in microdialysis rats but did not alter amphetaminestimulated DA release. These results suggest (1) NMDA receptor stimulation is required for the development of both autoreceptor subsensitivity in the VTA and postsynaptic $D_{1}$ receptor supersensitivity in the NAc during repeated amphetamine treatment, (2) these functional changes therefore appear to be closely associated with the development of behavioral sensitization, and (3) a dissociation can be demonstrated between the intensity of amphetamine-stimulated

Received July 20, 1993; accepted Sept. 9, 1993.

This work was supported by U.S. Public Health Service Grants DA-07735 (M.E.W.) and DA-04093 (F.J.W.) from the National Institute on Drug Abuse, the National Alliance for Research on Schizophrenia and Depression (M.E.W.), and the Pharmaceutical Manufacturers Association Foundation (M.E.W.).

Correspondence should be addressed to Dr. Marina E. Wolf, Department of Neuroscience, UHS/The Chicago Medical School, 3333 Green Bay Road, North Chicago, IL 60064-3095.

Copyright (C) 1994 Society for Neuroscience $0270-6474 / 94 / 141735-11 \$ 05.00 / 0$ behavioral responses and amphetamine-stimulated DA release in the NAC.

IKey words: NMDA receptors, dopamine autoreceptors, ventral tegmental area, nucleus accumbens, dopamine release]

Repeated administration of psychomotor stimulants such as amphetamine, cocaine, and morphine results in an augmentation of their locomotor stimulatory effects. This phenomenon is termed behavioral sensitization. Most sensitization research during the past decade has focused on dopamine (DA) systems because of overwhelming evidence that DA is involved in both the rewarding and locomotor stimulatory effects of amphetamine, cocaine, and morphine (for reviews, see Robinson and Becker, 1986; Kalivas and Stewart, 1991; White and Wolf, 1991). A number of functional changes in the mesoaccumbens DA system have been found to accompany behavioral sensitization, including augmentation of the ability of psychomotor stimulants to enhance extracellular concentrations of DA in the nucleus accumbens (NAc) (Robinson et al., 1988; Kalivas and Duffy, 1990, 1993a; Pettit et al., 1990; Kalivas and Stewart, 1991; Vezina, 1993), subsensitivity of DA autoreceptors located on DA cell bodies in the ventral tegmental area (VTA) (Kamata and Rebec, 1984; White and Wang, 1984b; Henry et al., 1989; Ackerman and White, 1990), and supersensitivity of $D_{1}$ receptors in the NAc (Higashi et al., 1989; Henry and White, 1991). It has been difficult, however, to establish whether such changes play a causal role in the development of sensitization. This is in large part due to the fact that variables such as stimulant dose, duration of the treatment regimen, and duration of the abstinence period prior to testing appear to influence whether or not these alterations in mesoaccumbens DA function can be demonstrated (Kalivas and Stewart, 1991; Wolf et al., 1993). Growing evidence suggests that behavioral sensitization can, in some cases, be dissociated from changes in DA function (Segal and Kuczenski, 1992a,b; Wolf et al., 1993).

These and other observations have led to the speculation that transmitters other than $\mathrm{D} \Lambda$ must also be involved in the development and expression of behavioral sensitization. It has been demonstrated recently that the development of behaviorai sensitization to amphetamine, cocaine, and morphine is prevented by coadministration of excitatory amino acid antagonists, including those which are selective for the $N$-methyl-Daspartate (NMDA) receptor (Karler et al., 1989, 1990, 1991; Wolf and Khansa, 1991; Wolf and Jeziorski, 1993; Jeziorski et al., in press). These findings suggest that NMDA receptor stim- 
ulation is required for the development of behavioral sensitization.

The present study examined whether coadministration of the noncompetitive NMDA antagonist MK-801 with amphetamine, utilizing a regimen that prevents behavioral sensitization, would also prevent changes in mesoaccumbens DA function associated with amphetamine sensitization. Our results suggest a close association between behavioral sensitization and both autoreceptor subsensitivity in the VTA and postsynaptic $D_{1}$ receptor supersensitivity in the $N \Lambda c$, in that all three phenomena appear to require NMDA receptor stimulation for their development. The idea that DA- and excitatory amino acidcontaining neurons interact to enable the expression of behavioral sensitization is consistent with the demonstrated importance of interactions between DA and excitatory amino acids in determining behavioral, and particularly locomotor, output (see Carlson and Carlson, 1990, for review). However, our results indicate that amphetamine-stimulated DA release in the NAc is similar in sensitized and nonsensitized rats, supporting previous reports that the expression of behavioral sensitization to amphetamine or cocaine can occur in the absence of alterations in DA release (Segal and Kuczenski, 1992a,b).

\section{Materials and Methods}

Subjects. Male Sprague-Dawley rats (Harlan, Indianapolis, IN), weighing $225-250 \mathrm{gm}$ at the start of the experiment, were used in these studies. They were housed two per cage with food and water available ad libitum in a colony room that was maintained under constant temperature and humidity on a $12 \mathrm{hr}$ light/dark cycle (7:00 A.M. on, 7:00 P.M. off). Rats were allowed at least 1 week of habituation to the animal colony before any treatment began.

Drug treatment. Rats were treated once a day for $5 \mathrm{~d}$ with double injections (separated by $30 \mathrm{~min}$ ) of either water $/$ water, water $/ 5 \mathrm{mg} / \mathrm{kg}$ amphetamine, $0.1 \mathrm{mg} / \mathrm{kg} \mathrm{MK-801/water,} \mathrm{or} \mathrm{MK-801/amphetamine.}$ All injections were administered in home cages. We have shown previously that (1) this regimen results in behavioral sensitization to a subsequent challenge injection of amphetamine, (2) this sensitization persists for at least $10 \mathrm{~d}$, and (3) coadministration of MK-801 as described above prevents the development of sensitization in this regimen (Wolf and Jeziorski, 1993).

VTA single-unit recording. Procedures for extracellular recording from VTA (A10) DA neurons have been detailed previously (Henry et al., 1989). Recording electrodes were made by pulling glass tubing $(2.0 \mathrm{~mm}$ o.d.), which was prefilled with fiber glass, and breaking the tip back to $1-2 \mu \mathrm{m}$. These electrodes were filled with $2 \mathrm{M} \mathrm{NaCl}$ saturated with $1 \%$ $(\mathrm{w} / \mathrm{v})$ fast green dye and typically exhibited in vitro impedances of 2-4 $\mathrm{M} \Omega($ at $135 \mathrm{~Hz}$ ). Electrode potentials were passed through a high-impedance amplifier/filter and displayed on an oscilloscope. Individual action potentials were discriminated electronically and monitored on a audio amplifier. Integrated rate histograms, generated by the output of the window discriminator, were plotted by a polygraph recorder while digitized counts of cellular activity were obtained for off-line analysis.

Rats were anesthetized with chloral hydrate $(400 \mathrm{mg} / \mathrm{kg}$, i.p. $)$ and mounted in a stereotaxic frame. A thermostatically controlled heating pad was used to maintain body temperature at $36-37^{\circ} \mathrm{C}$. A lateral tail vein was cannulated with a 25 gauge $3 / 4$ inch needle through which additional anesthetic was administered as needed. A burr hole was drilled in the skull and the dura mater was retracted from the area overlying the VTA (A 3.0-3.5, L 0.5-1.5, V 6.5-8.0, according to Paxinos and Watson, 1986). A hydraulic microdrive was used to lower the electrodes through the VTA. A 10 DA cells were identified by standard physiological criteria (Bunney et al., 1973; Wang, 1981) and were recorded for 3-6 min to establish a baseline firing rate. To determine the sensitivity of impulse-regulating somatodendritic autoreceptors on A10 DA cells (White and Wang, 1984c), each rat was administered the DA agonist apomorphine through the cannulated tail vein. The drug was injected using a cumulative dose regimen in which each dose doubled the previous dose, at $1 \mathrm{~min}$ intervals. At the end of each experiment, the cell location was marked by ejecting fast green dye and the spot was verified by routine histological assessment. All surgical procedures were performed in strict accordance with the National Institutes of Health Guide for the Care and Use of Laboratory Animals.

Between-group comparisons were performed using a two-way ANOVA (group $\times$ dose) with dose as a repeated measure. Subsequent planned comparisons between groups were conducted with a $t$ test. Regression analysis was used to determine the $\mathrm{ED}_{20}$ for apomorphine-induced inhibition of each neuron and these values were averaged for each group. Because the sensitivity of A10 DA neurons to apomorphine and other DA agonists is determined, in part, by the basal firing rate of the cell (White and Wang, 1984a), a variable that can be altered by repeated amphetamine treatment (White and Wang, 1984b), analysis of covariance (using basal firing rate as the covariate) was conducted on the $E D_{50}$ values to ensure that any observed differences between the treatment groups were not due to different basal firing rates (White and Wang, 1984b).

NAC single-unit recordings. Procedures for recording from NAc neurons have been detailed previously (Henry and White, 1991). Surgical procedures, recording techniques, and data analysis were as described above. For NAc neurons, however, five-barrel glass pipettes were used. The $\mathrm{D}_{1}$ agonist SKF 38393 and the $\mathrm{D}_{2}$ agonist quinpirole (each at 10 $\mathrm{mm}, \mathrm{pH} 4.0$ ) were administered iontophoretically. Most NAc neurons were quiescent and were driven to fire by iontophoretic pulses of glutamatc $(10 \mathrm{~mm}, \mathrm{pH} 8.0)$, which lasted for $30 \mathrm{sec}$, with $40 \mathrm{sec}$ "off periods" between each pulse. SKF 38393 and quinpirole were administered in a cumulative current manner (2-64 nA) such that each current was tested during two glutamate pulses. Automatic current neutralization, through one side barrel containing $2 \mathrm{M} \mathrm{NaCl}$, was used to prevent current artifacts. At the end of each recording, electrode location was marked by iontophoretic administration of fast green dye. Data are presented as changes in the percentage of basal firing rate.

Microdialysis. Microdialysis probes were constructed essentially as described by Robinson and Whishaw (1988). However, to allow easy insertion and removal of probes, $26 \mathrm{gm}$ internal cannulas and interlocking $21 \mathrm{gm}$ guide cannulas from Plastics One (Roanoke, VA) were used to construct probes and guides, respectively. Guide cannulas, once implanted, extended $1 \mathrm{~mm}$ below the skull. The stainless steel portion of the probes cxtcnded $5 \mathrm{~mm}$ bclow the guide, with an additional $2 \mathrm{~mm}$ of dialysis membrane (MW cutoff, 6000 ; dialysis membrane o.d., 250 $\mu \mathrm{m}$; Spectrum, Los Angeles, CA) extending into the NAc. Coordinates for the tip of the probes were 1.7 A, 1.3 L, 8.0 V (Paxinos and Watson, 1986). Using naive rats, guide cannulas were stereotaxically implanted at these coordinates under sodium pentobarbital anesthesia $(60 \mathrm{mg} / \mathrm{kg}$, i.p.) 3-5 d before drug injections began, and secured using dental cement and two skull screws. After surgery, rats were housed alone in standard Plexiglas rat cages. Drug injections were performed in home cages as described above. On the evening before the seventh day of drug abstinence, rats were transferred to Plexiglas dialysis cages designed to resemble home cages as closely as possible. Dialysis probes were inserted the next morning and perfused at $2 \mu \mathrm{l} / \mathrm{min}$ with artificial cerebrospinal fluid consisting of (in mM) $2.7 \mathrm{KCl}, 140 \mathrm{NaCl}, 1.2 \mathrm{CaCl}_{2}, 1.0 \mathrm{MgCl}_{2}$, $0.3 \mathrm{NaH}_{2} \mathrm{PO} 4$, and $1.7 \mathrm{Na}_{2} \mathrm{HPO}_{4}(\mathrm{pH} 7.4)$. Prior to placing the probe in the rat, probe recovery was determined in vitro using a $10 \mathrm{ng} / \mathrm{ml}$ solution of DA. Recovery was expressed as the average of three $20 \mathrm{~min}$ fractions obtained while perfusing the probe at a rate of $2 \mu \mathrm{l} / \mathrm{min}$. All data were corrected for probe recovery to enable normalization of differences between probes and to enable data to be expressed as fmol/ min for comparison to other values in the literature; in vitro calibration cannot, however, be used to calculate absolute extracellular levels because in vitro recovery will not accurately predict in vivo recovery (Benveniste et al. 1989). Once the probe was lowered into the NAc, dialysate was collected every $20 \mathrm{~min}$ and analysed for DA levels using HPLC with electrochemical detection. After stable DA levels were obtained in three consecutive samples (this typically required $2 \mathrm{hr}$ ), rats received a challenge injection of $1.0 \mathrm{mg} / \mathrm{kg}$ amphetamine and fractions were collected for 3 additional hours. During this time, rats were scored by a trained observer (during the middle $10 \mathrm{~min}$ of each fraction) for the degree of amphetamine-induced locomotor activity based on a standard scale described in Results (Creese and Iverson, 1974). Following each experiment, probe placement was verified histologically. Data were analyzed using two-way ANOVA (group $\times$ time) with time as the repeated measure.

$H P L C$. Chromatographic conditions were optimized for early elution of DA to obtain maximum sensitivity. The system consisted of a BAS Phase II ODS $3 \mu \mathrm{m}$ column $(100 \times 3.2 \mathrm{~mm})$, a BAS LC4B electrochemical detector, and a Scientific Systems, Inc. model 222C HPLC 


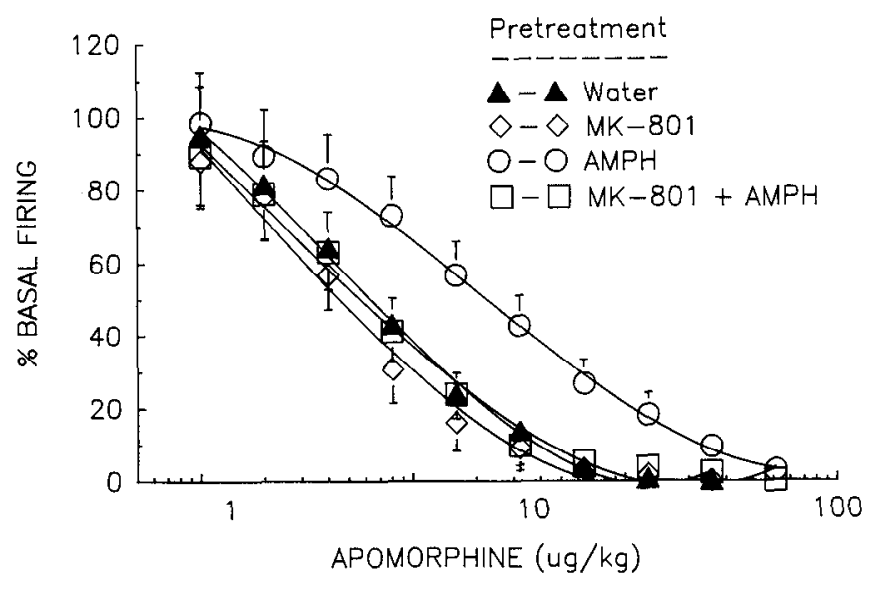

Figure 1. Cumulative dose-response curves showing that coadministration of MK-801 prevents the ability of repeated amphetamine treatment to induce subsensitivity of A10 DA neurons to the inhibitory effects of apomorphine. Dopamine neurons recorded from repeated amphetamine rats were markedly less sensitive to apomorphine than those tested in the three other groups, at all doses of apomorphine except the two lowest and two highest. Each data point represents the mean \pm SEM from eight cells.

pump. Mobile phase consisted of $0.1 \mathrm{M} \mathrm{NaH}_{2} \mathrm{PO}_{4}, 0.05$ mm EDTA, 2.1 mM 1-octane-sulfonic acid, and 13-16\% ( $\mathrm{v} / \mathrm{v})$ methanol (depending on column age), adjusted to $\mathrm{pH} 4.9$ and pumped at a rate of $1 \mathrm{ml} / \mathrm{min}$. Peaks were recorded using a dual-channel chart recorder and quantified by comparison with the peak heights of standards run with every experiment.

Drugs. Amphetamine sulfate was purchased from Sigma Chemical Co. (St. Louis, MO). Apomorphine $\mathrm{HCl}, \mathrm{SKF} 38393 \mathrm{HCl}$, quinpirole $\mathrm{HCl}$, and (+)MK-801 maleate were purchased from Research Biochemicals Inc. (Natick, MA). All drugs were dissolved in water and all doses refer to weights of the respective salts.

\section{Results}

$D A$ autoreceptors in VTA

Previous studies in our laboratories have demonstrated that subsensitivity of DA autoreceptors in the VTA is most pronounced after short periods of abstinence from repeated amphetamine treatment and cannot be demonstrated after withdrawals of 10-14 d (White and Wang, 1984b; Wolf et al., 1993). The present experiments were therefore carried out after $1 \mathrm{~d}$ of abstinence from 5 consecutive days of treatment with either water/water, water $/ 5 \mathrm{mg} / \mathrm{kg}$ amphetamine, $0.1 \mathrm{mg} / \mathrm{kg} \mathrm{MK}-801 /$ water, or MK-801/amphetamine (see Materials and Methods for details). The sensitivity of A10 DA neurons to intravenous apomorphine was determined by conventional extracellular single-unit recording techniques. As previously demonstrated using somewhat different treatment regimens (Kamata and Rebec, 1984; White and Wang, 1984b; Wolf et al., 1993), repeated administration of amphetamine significantly reduced the sensitivity of VTA DA neurons to the inhibitory effects of apomorphine (Fig. 1). This effect was prevented by coadministration of MK-801. Repeated-measures ANOVA on the four treatment groups revealed a significant groups effect $[F(3,24)=$ $6.96, p<0.01]$, and planned comparison $t$ tests showed that this effect was due completely to the water/amphetamine group. Thus, the inhibition by apomorphine in this group was significantly reduced as compared to all other groups at all but the two lowest and two highest doses of apomorphine challenge (Fig. 1). ANCOVA revealed an overall significant difference between the apomorphine $\mathrm{ED}_{50}$ values for the four groups $[F(3,27)$

\section{A Water}

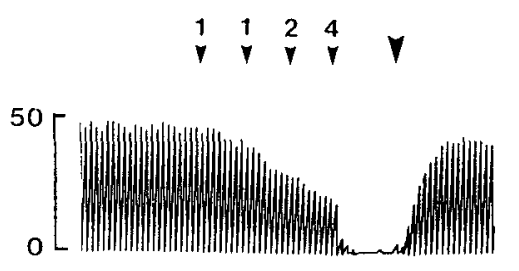

B $M K-801$

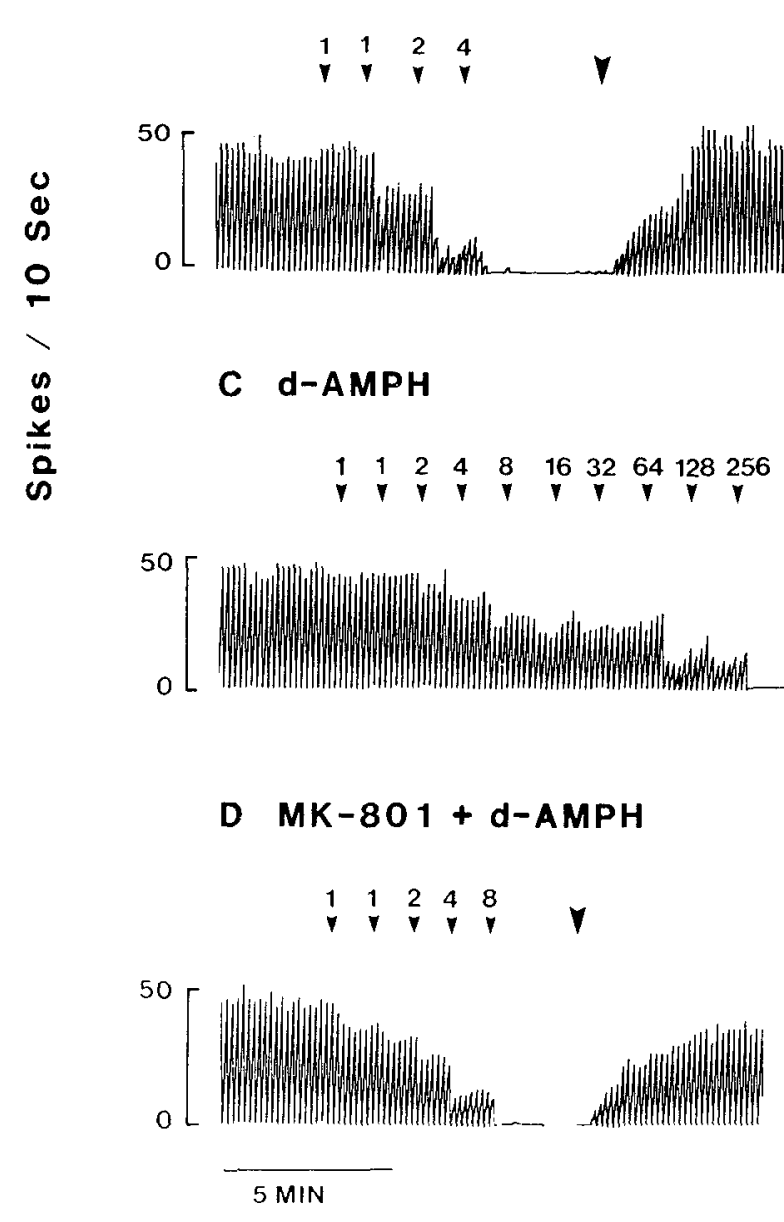

Figure 2. Representative cumulative rate histograms illustrating the inhibitory effects of intravenous apomorphine on A10 DA neurons recorded from the four treatment groups. In each trace, the small arrowheads indicate injections of apomorphine at the doses indicated $(\mu \mathrm{g} /$ $\mathrm{kg}$ ), and the large arrowheads indicate injection of the $\mathrm{D}_{2}$ dopamine receptor antagonist eticlopride $(0.1 \mathrm{mg} / \mathrm{kg})$, which was used to reverse the inhibition and to confirm that the cells were still capable of activity (i.e., they had not been "lost"). $A$, This DA neuron, recorded from a saline-treated control rat, was almost completely inhibited by a total cumulative dose of $8 \mu \mathrm{g} / \mathrm{kg}$ apomorphinc. $B$, Inhibition of this DA neuron recorded from a rat that had received repeated MK-801 was similar to that observed in saline-treated controls. $C$, This cell, recorded from a rat that received repeated amphetamine treatment, was markedly less sensitive to the inhibitory effects of apomorphine. Note that a total dose of $512 \mu \mathrm{g} / \mathrm{kg}$ was required to achieve complete inhibition of activity. $D$, Coadministration of MK-801 prevented the subsensitivity of A10 DA neurons to apomorphine as indicated by comparing this cell to that depicted in $C$. 

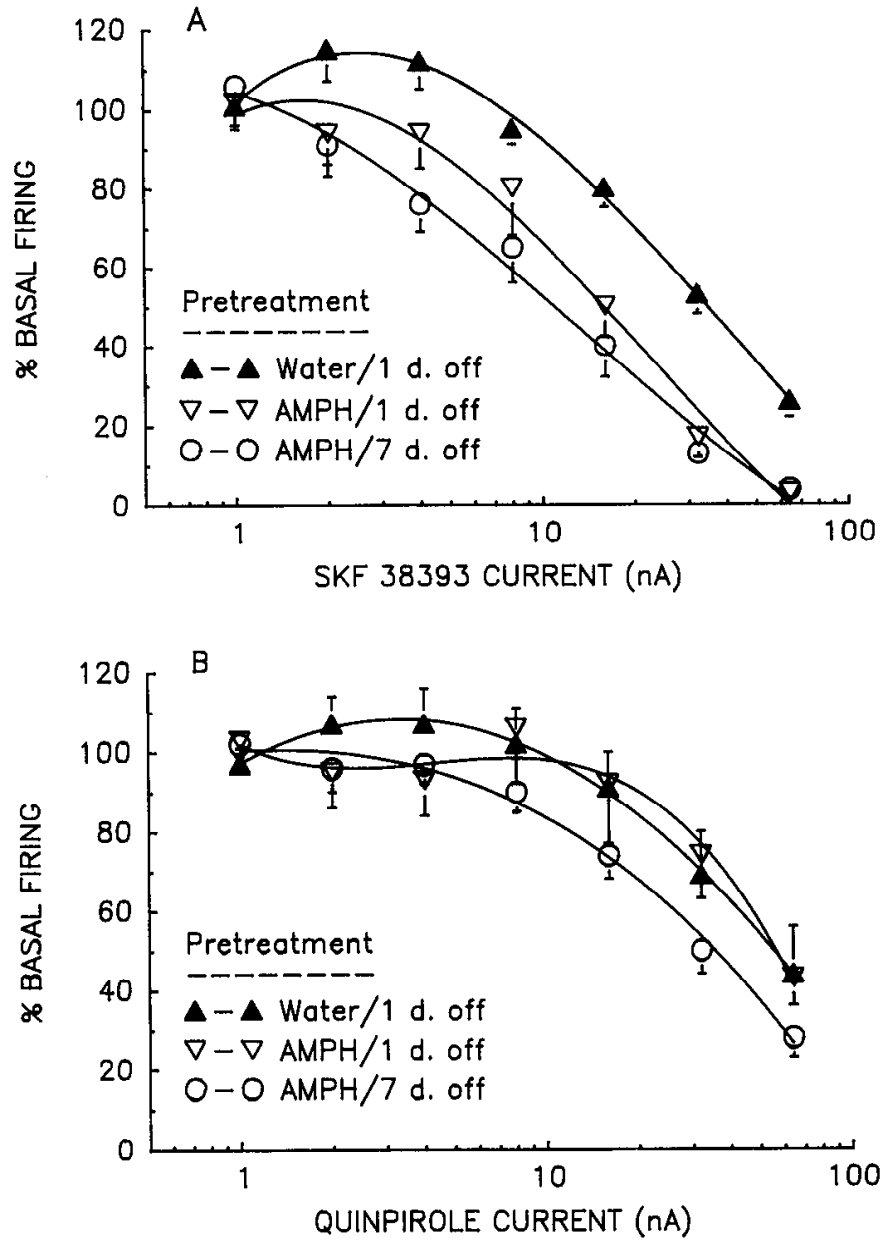

Figure 3. Current-response curves indicating the enhanced sensitivity of NAc neurons to the inhibitory effects of the $D_{1}$ agonist SKF 38393 $(A)$, but not the $\mathrm{D}_{2}$ agonist quinpirole $(B)$, in rats injected repeatedly with amphetamine and withdrawn for either 1 or $7 \mathrm{~d}$. For the SKF 38393 current-response curves in $A$, both the 1 and $7 \mathrm{~d}$ off groups were significantly more sensitive to SKF 38393 at all but the lowest ( $1 \mathrm{nA}$ ) currents $(p<0.05)$. Note the trend toward enhanced sensitivity to quinpirole in the $7 \mathrm{~d}$ off group in $B$. Each data point represents the mean \pm SEM of $10-12$ cells.

$=7.18, p<0.01 \mathrm{l}$, and planned comparison $t$ tests again indicated that this significant effect was due completely to the water/ amphetamine group. Thus, as compared to the water/water control group $\left(\mathrm{ED}_{50}=7.9 \pm 1.7 \mu \mathrm{g} / \mathrm{kg}\right)$, the $\mathrm{MK}-801 /$ water group $\left(E_{50}=9.7 \pm 3.9\right)$, and the MK-801/amphetamine group $\left(\mathrm{ED}_{50}\right.$ $=9.9 \pm 7.2)$, the water/amphetamine group $\left(\mathrm{ED}_{50}=31.5 \pm\right.$ 7.2) was significantly less sensitive to apomorphine, an effect which could not be attributed to differences in the basal firing rates of the cells in the different groups. None of the other groups differed significantly from one another. Examples illustrating the inhibitory effects of apomorphine in each of the repeated treatment groups are shown in Figure 2.

\section{$D_{1}$ and $D_{2}$ receptors in $N A C$}

The sensitivity of $D_{1}$ and $D_{2}$ receptors in the NAc to iontophoretic application of the $D_{1}$-selective agonist SKF 38393 or the $\mathrm{D}_{2}$-selective agonist quinpirole, respectively, was evaluated using conventional single-unit recording techniques. First, $D_{1}$ and $\mathrm{D}_{2}$ receptor sensitivity were compared in water/water versus water/amphetamine rats after either 1 or $7 \mathrm{~d}$ abstinence from
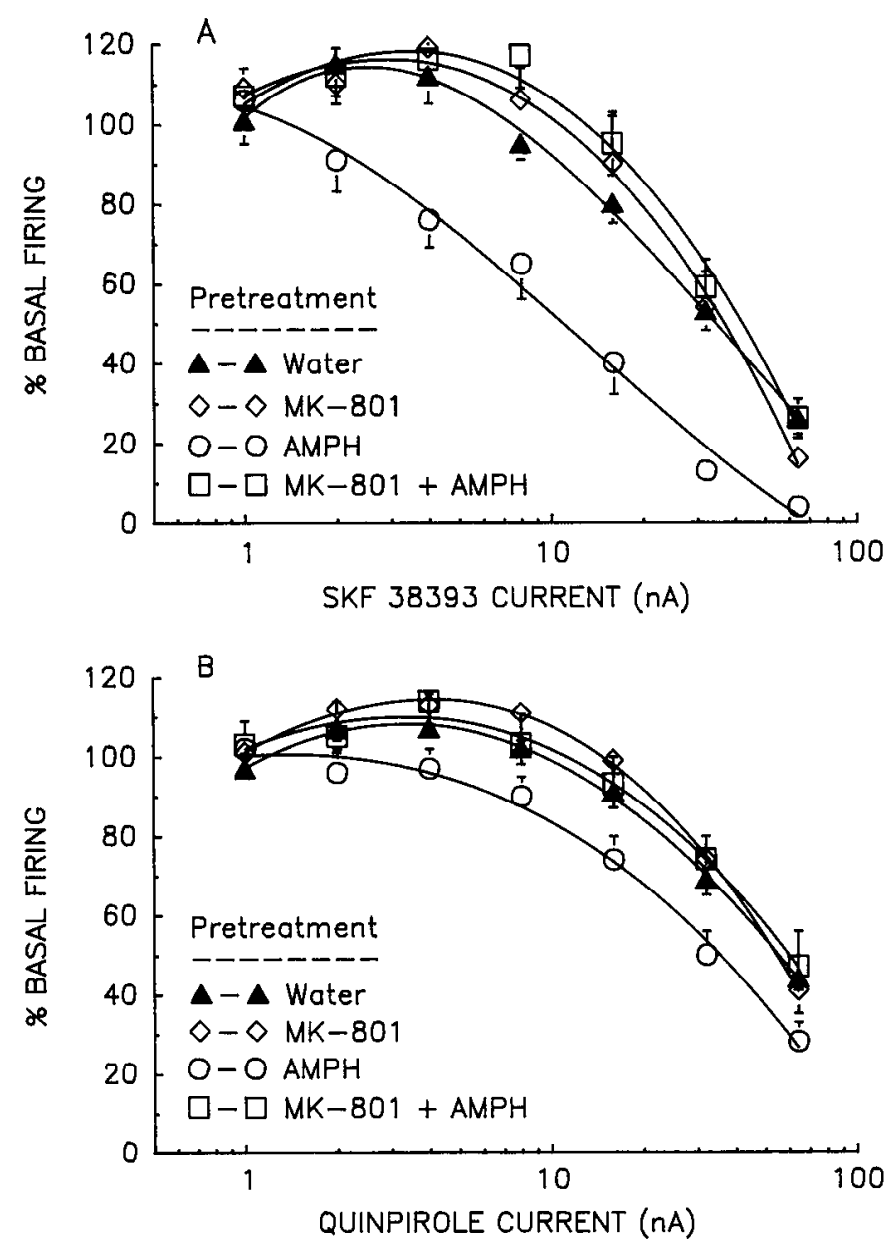

Figure 4. Current-response curves indicating that coadministration of MK-801 prevents the development of NAc $D$, receptor supersensitivity during repeated amphetamine administration. $A$, The supersensitivity of $D_{1}$ receptors induced by repeated amphetamine treatment is completely blocked by coadministration of $\mathrm{MK}-801$, which given alone failed to influence the sensitivity of nucleus neurons to the $D_{1}$ agonist SKF 38393. The amphetamine group $(A M P H)$ differed from all other groups at all currents of SKF 38393 except $1 \mathrm{nA}$. $B$, Note that the trend toward supersensitivity of NAc neurons to the $D_{2}$ agonist quinpirole observed in the AMPH group was not evident in the MK-801 + AMPH group. Each data point represents the mean \pm SEM of 10-13 cells in each group.

repeated treatment (Fig. 3). $\mathrm{D}_{1}$ receptors exhibited supersensitivity to SKF 38393 at both times [1 d: $F(1,20)=10.81, p<$ $0.01 ; 7 \mathrm{~d}: F(1,22)=20.09, p<0.001]$, although supersensitivity was somewhat more pronounced after $7 \mathrm{~d}$ of abstinence (Fig. $3 A) . \mathrm{D}_{2}$ receptors did not exhibit significant changes in sensitivity to quinpirole $[1 \mathrm{~d}: F(1,20)=0.02, \mathrm{NS} ; 7 \mathrm{~d}: F(1,22)=$ $1.61, \mathrm{NS}]$, although there was a slight trend toward supersensitivity after $7 \mathrm{~d}$ of abstinence (Fig. $3 B$ ).

The effects of MK-801 coadministration on $\mathrm{D}_{1}$ and $\mathrm{D}_{2}$ receptor sensitivity was examined after $7 \mathrm{~d}$ of abstinence. As shown in Figure $4 A, \mathrm{D}_{1}$ receptor supersensitivity was completely prevented by coadministration of MK-801 [MK-801/amphetamine vs water/water: $F(1,23)=1.99, \mathrm{NS}$, while MK- 801 by itself exerted no effect on $D_{1}$ receptor sensitivity [MK-801/water vs water/water: $F(1,22)=0.19$, NS]. Similarly, the slight but nonsignificant increase in $D_{2}$, receptor sensitivity observed after $7 \mathrm{~d}$ abstinence appeared to be prevented by MK-801 coadministration, while MK-801 alone exerted no effect on $D_{2}$ receptor 
A Water

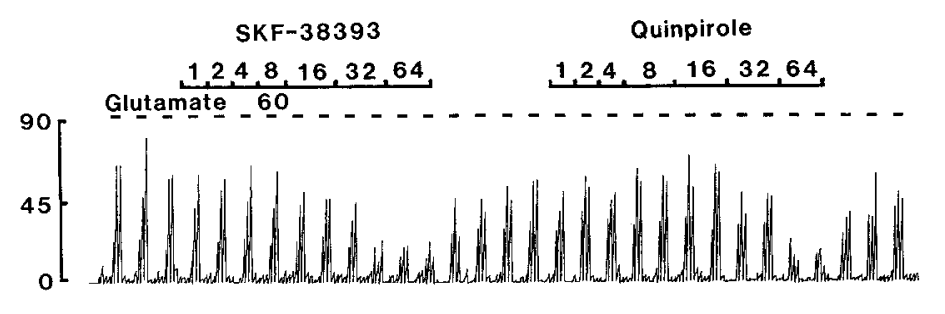

B $\quad M K-801$

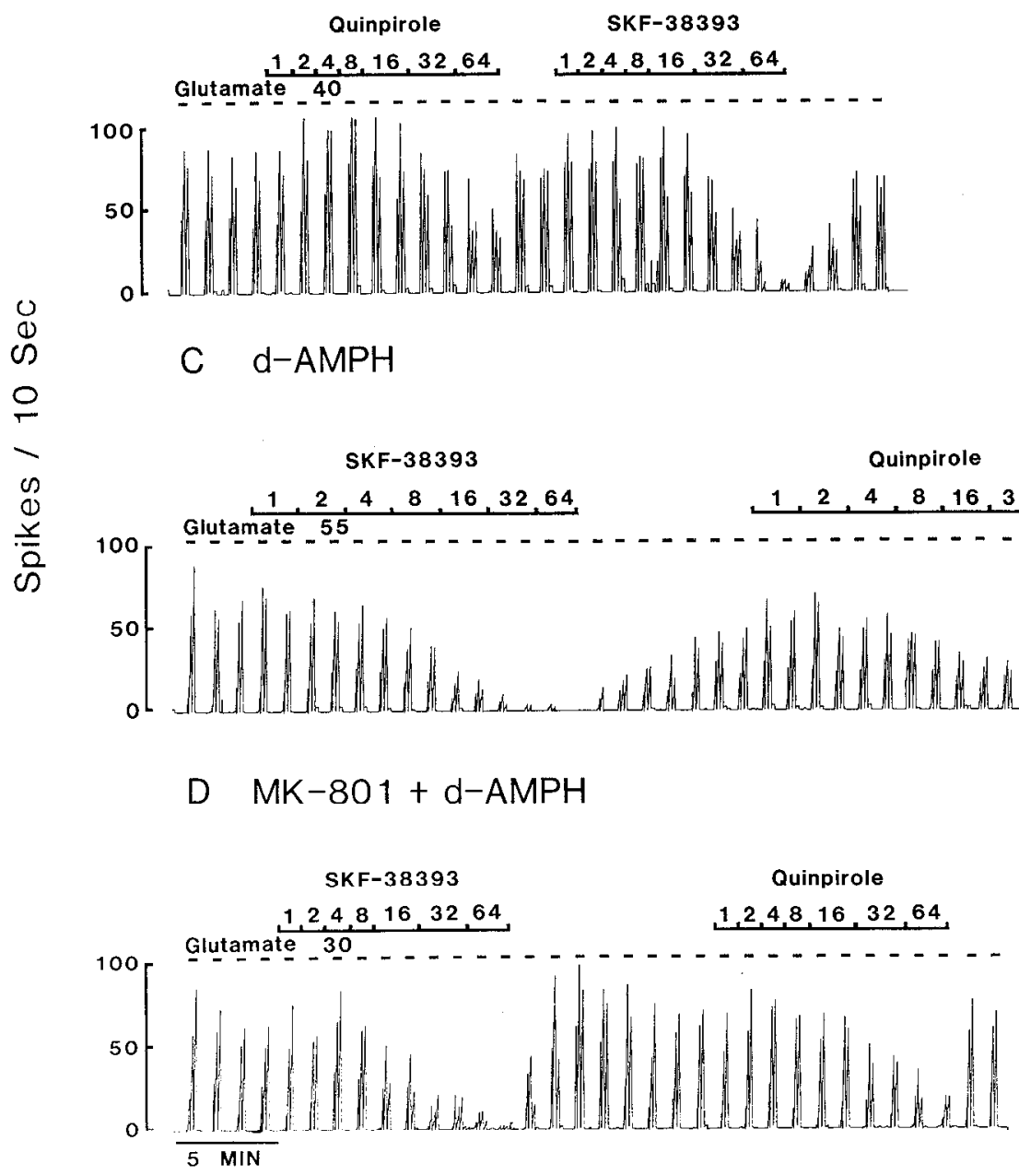

Figure 5. Representative cumulative rate histograms illustrating the ability of repeated amphetamine treatment to cause an enhanced response of NAc neurons to iontophoretic administration of the $\mathrm{D}_{1}$ agonist SKF 38393, and the ability of coadministration of MK801 to prevent the effect. $A$, Inhibition of a glutamate-driven accumbens neuron by increasing currents applied through the barrels containing SKF 38393 and quinpirole in a rat that had received repeated injections of saline. $B$, Failure of repeated treatment with MK-801 alone to influence the sensitivity of this accumbens neuron to SKF 38393 or quinpirole. $C$, Clear supersensitivity of an accumbens neuron to SKF 38393 in a rat that had received repeated administration of $d$-amphetamine $(d-A M P H)$. $D$, Prevention of $\mathrm{D}_{1}$ receptor supersensitivity by coadministration of MK-801 and $d$-amphetamine. Lines and numbers represent duration of iontophoretic administration and currents (in nanoamperes), respectively. sensitivity $\left[F(1,22)=0.25\right.$, NS] (Fig. $4 B$ ). Examples of $\mathrm{D}_{1}$ supersensitivity and its reversal by $\mathrm{MK}-801$ coadministration are shown in Figure 5.

\section{Amphetamine-stimulated $D A$ release in $N A C$}

The elevation of extracellular DA levels elicited by a challenge injection of amphetamine ( $1 \mathrm{mg} / \mathrm{kg}$, i.p.) was evaluated after 7 $\mathrm{d}$ of abstinence. A challenge dose lower than the treatment dose ( $5 \mathrm{mg} / \mathrm{kg}$, i.p.) was selected because we have found that this enables sensitized rats to be readily distinguished from naive or water-treated rats based on simple observational scoring (Wolf and Jeziorski, 1993, and unpublished findings) and because the types of locomotor activity elicited by low doses of amphetamine have been shown to correlate with DA release in the NAc (Sharp et al., 1987).
Because microdialysis studies were performed in awake rats, it was possible to compare the neurochemical and behavioral responses to amphetamine challenge by scoring the intensity of amphetamine-induced locomotor activity during the microdialysis experiments according to a standard locomotor activity scale (Creese and Iversen, 1974): 0, asleep or stationary; 1, alert; 2 , active, with bursts of stereotyped sniffing or rearing; 3 , stereotyped locomotor activity, manifest in the present experiments as crossing the cage, rearing, and crossing back (i.e., activity along a fixed path); 4, stereotyped sniffing or rearing, maintained in one location; 5 , stereotyped behavior in one location with bursts of gnawing or licking; 6 , continual gnawing or licking.

Figure 6 compares the behavioral response to amphetamine challenge in each of the four repeated treatment groups (water/ 


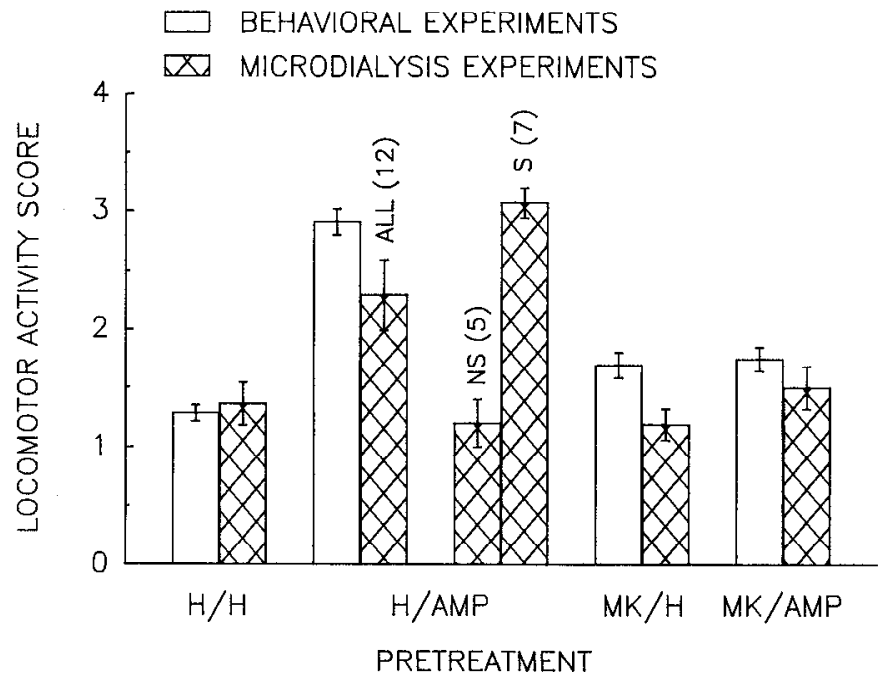

Figure 6. Locomotor activity scores showing response to amphetamine challenge following pretreatment with either water/water $(H / H)$, water/amphetamine $(H / A M P)$, MK-801/water $(M K / H)$, or MK-801/ amphetamine $(M K / A M P)$. Open bars show data from rats tested in behavioral experiments only, while crosshatched bars show data from rats implanted with microdialysis probes and observed during the course of microdialysis experiments. The three crosshatched bars shown for the H/AMP microdialysis group indicate, respectively, combined results from all rats in this group $(A L L)$, and results from nonsensitized rats ( $N S$; defined as scoring below a 3 on the locomotor activity scale) and sensitized rats ( $S$; defined as scoring a 3 or more). Coadministration of MK- 801 prevented the development of sensitization in both behavioral and microdialysis rats (see Results for statistical analysis). For behavioral experiments, $n=6$ rats/group; for microdialysis experiments: water/water, $n=7$; water/amphetamine (sensitized), $n=7$; water/amphetamine (nonsensitized), $n=5$; MK-801/water, $n=8$; MK-801/ amphetamine, $n=6$.

water, water/amphetamine, MK-801/water, and MK-801/amphetamine) under two different experimental conditions. Open bars show results obtained in rats tested for behavioral responses only (no dialysis probes implanted), while crosshatched bars show results obtained in the same experimental groups during microdialysis experiments (different rats, with probes implanted). In both cases, each rat was scored once every $20 \mathrm{~min}$ and scores from the first hour, during which behavioral responses were most intense, were averaged. In microdialysis experiments, rats typically slept during the $1-2 \mathrm{hr}$ period prior to amphetamine challenge.

In rats tested for behavior only, amphetamine-induced locomotor activity was significantly more intense in water/amphetamine rats, but not MK-801/amphetaminc or MK-801/ water rats, as compared to water/water controls (Newman-Keuls' test, $p<0.05$ ). These results confirm that this treatment regimen elicits behavioral sensitization that is evident after $7 \mathrm{~d}$ abstinence and that sensitization is prevented by coadministration of MK-801 (Wolf and Jeziorski, 1993). In microdialysis rats, a similar pattern was observed, except that water/amphetamine rats did not sensitize as uniformly as in behavioral studies. For purposes of comparison, water/amphetamine rats in microdialysis experiments ( $n=12$ total) were therefore divided into two groups: those that exhibited robust sensitization $(n=7)$, defined as achieving a 3 on the locomotor activity scale, and those that did not $(n=5)$. The three hatched bars for the water/ amphetamine group in Figure 6 show, respectively, combined
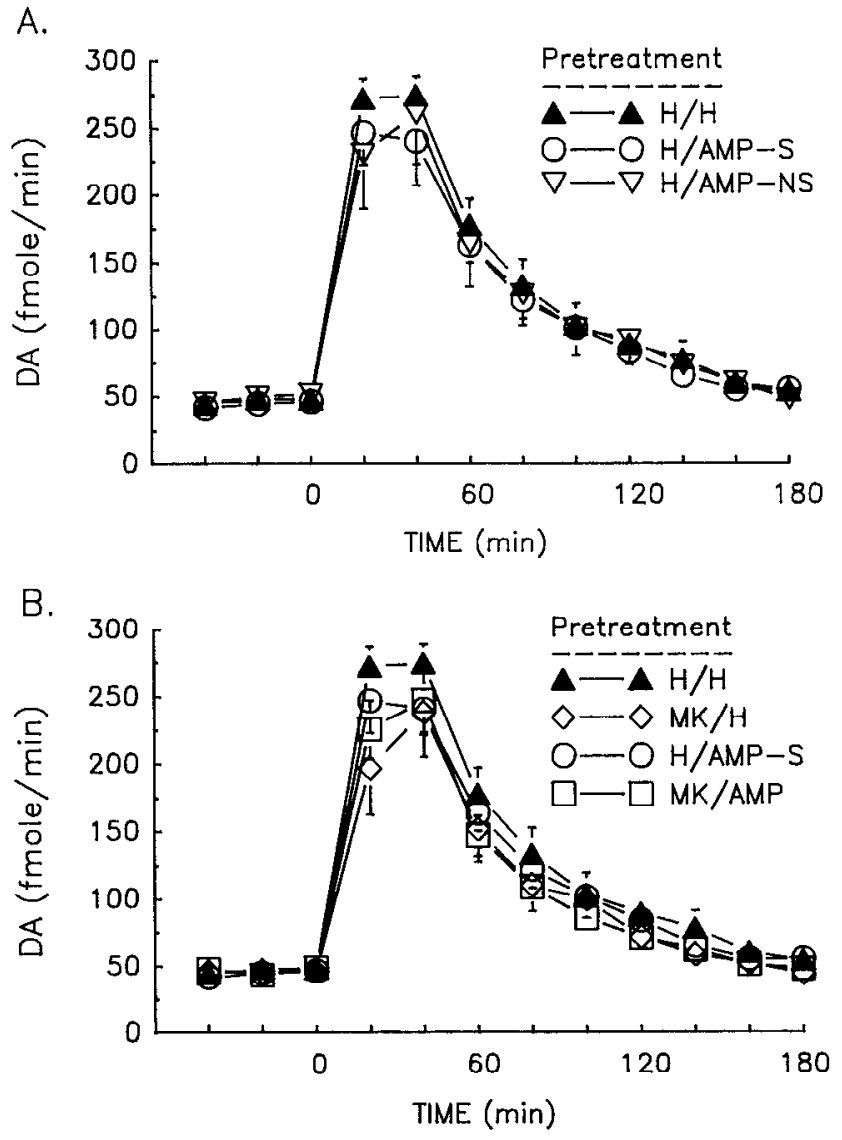

Figure 7. Comparison of the effect of a challenge injection of amphetamine $(1 \mathrm{mg} / \mathrm{kg}$, i.p.) on extracellular DA levels in the NAc of rats in each of the four repeated treatment groups. $A$, No significant differences in amphetamine-stimulated DA levels were found between water/ water rats $(H / H)$, water/amphetamine rats exhibiting a sensitized behavioral response to amphetamine challenge $(H / A M P-S$; defined as scoring a 3 or more on the locomotor activity scale shown in Fig. 6), and water/amphetamine rats failing to exhibit sensitization (H/AMP$N S$; defined as scoring below a 3 ). $B$, No significant differences in amphetamine-stimulated levels were found between water/water rats $(H /$ $H)$, MK-801/water rats $(M K / H)$, water/amphetamine rats exhibiting a sensitized response $(H / A M P-S)$, and MK-801/amphetamine rats (MK/ $A M P)$. These results demonstrate that amphetamine challenge produces the same DA response in the NAc regardless of whether rats express a sensitized behavioral response (water/amphetamine group) or fail to do so (water/water, MK-801/water, and MK-801/amphetamine groups). Baseline DA levels did not differ between the treatment groups (see Results). The behavioral data presented in Figure 6 were obtained during the course of the microdialysis experiments presented in this figure. See Results for statistical analysis.

data from all rats, data from nonsensitized rats only, and data from sensitized rats only. If combined data from all 12 microdialysis rats are considered, sensitization appeared less robust than in behavioral experiments, although it was still statistically significant ( $p<0.05$ relative to water/water rats, NewmanKeuls' test). The sensitized microdialysis rats $(n=7)$ were as robustly semsitized as behavioral rats, while the nonsensitized microdialysis rats $(n=5)$ were not significantly different than water/water controls from either behavioral or microdialysis experiments. Coadministration of MK-801 in microdialysis experiments prevented sensitization (water/amphetamine vs MK801/amphetamine: $p<0.05$, Newman-Keuls' test). MK-801/ water rats in microdialysis experiments were not significantly 
different from water/water microdialysis rats, but did exhibit more intense locomotor activity than MK-801/water rats in behavioral experiments ( $p<0.05, t$ test).

Although it is unclear why a significant number of water/ amphetamine rats failed to exhibit sensitization in microdialysis experiments (see Discussion), this enabled several interesting comparisons to be made between behavioral and neurochemical responses to amphetamine challenge. Figure $7 A$ compares amphetamine-stimulated DA levels in the NAc in water/water controls, water/amphetamine rats that exhibited sensitization, and water/amphetamine rats that failed to exhibit sensitization. $\mathrm{Re}$ peated-measures ANOVA on the three treatment groups revealed no significant group effect $[F(2,16)=0.21$, NS] or group $\times$ time effect $[F(16,128)=0.48, \mathrm{NS}]$. These results demonstrate that amphetamine challenge elicits a similar increase in extracellular DA levels in the NAc in control, sensitized, and nonsensitized rats, suggesting a dissociation between the expression of sensitized behaviors and this neurochemical response. Planned comparison Newman-Keuls' tests revealed no significant differences between postamphetamine fractions for the three treatment groups.

Figure $7 B$ compares amphetamine-stimulated DA levels in rats from all four repeated treatment groups. Data from sensitized rats only are presented for the water/amphetamine group. Coadministration of MK-801, while blocking the development of behavioral sensitization (see Fig. 6), had no effect on amphetamine-stimulated DA levels in NAc, again suggesting a dissociation between behavioral and neurochemical responses. Repeated-measures ANOVA on the four treatment groups revealed no significant group effect $[F(3,23)=0.63, \mathrm{NS}]$ or group $\times$ time effect $[F(24,184)-0.66, \mathrm{NS}]$. Amphetamine-stimulated DA levels in MK-801/water rats appeared to be slightly lower than in water/water controls, although planned comparison Newman-Keuls' tests revealed no statistically significant differences between postamphetamine fractions among the four treatment groups. Interestingly, examination of data from individual rats revealed that the two rats in the MK-801/water group with the lowest amphetamine-stimulated DA levels exhibited the most intense locomotor activity, although this correlation did not hold for all rats in the group (data not shown).

Baseline DA levels, defined as the average of the three $20 \mathrm{~min}$ dialysis samples prior to amphetamine injection, did not differ significantly between treatment groups (data expressed as fmol/ $\mathrm{min}$ and corrected for probe recovery: water/water, $46.3 \pm 5.1$, $n=7$; MK-80I/water, $45.5 \pm 2.5, n=8$; water/amphetaminesensitized, $45.2 \pm 3.8, n=7$; water/amphetamine-nonsensitized, $49.0 \pm 4.0, n=5$; MK-801/amphetamine, $45.9 \pm 3.2, n$ $=6$ ). It should be noted that none of the results described above were altered if amphetamine-stimulated DA levels were expressed as percentage of baseline DA levels rather than as $\mathrm{fmol} /$ $\min$.

\section{Discussion}

These findings demonstrate a close association between behavioral sensitization to amphetamine and two accompanying functional changes in the mesoaccumbens DA system: the development of DA autoreceptor subsensitivity in the VTA and postsynaptic $D_{1}$, receptor supersensitivity in the NAc. First, we have shown that behavioral sensitization produced by repeated amphetamine administration is associated with both autoreceptor subsensitivity and $D_{1}$ receptor supersensitivity. The latter effect is quite similar to that previously demonstrated in the NAc of cocaine-sensitized rats (Henry and White, 1991). Supersensitivity of $D_{1}$ receptor-mediated responses within the NAc has also been demonstrated using in vitro intracellular recordings in rats that had received repeated methamphetamine injections (Higashi et al., 1989). Second, we have shown that coadministration of an NMDA antagonist with amphetamine, which prevents the development of behavioral sensitization, also prevents these changes in mesoaccumbens function. Since autoreceptor subsensitivity and $D_{1}$ supersensitivity would both tend to enhance DA transmission at the level of the NAc, it seems likely that these changes contribute to the enhanced locomotor responses to psychomotor stimulants exhibited by sensitized animals. The observation that both behavioral sensitization to amphetamine and these associated changes in mesoaccumbens DA function are dependent on NMDA receptor stimulation for their development strengthens the argument for a causal link between these phenomena.

Previous studies have suggested that changes in mesoaccumbens DA function that accompany sensitization may occur sequentially, contributing to a cascade of events that ultimately results in sensitization. Subsensitivity of DA autoreceptors in the VTA (Kamata and Rebec, 1984; White and Wang, 1984b) and the resulting increase in DA cell activity (White and Wang, 1984b) appear to be very early events that may be necessary for the initiation of sensitization (Ackerman and White, 1990; Henry and White, 1991; Wolf et al., 1993). This is consistent with studies demonstrating that behavioral sensitization after repeated amphetamine treatment appears to require alterations within the VTA. Thus, despite the fact that administration of amphetamine directly into the VTA has no acutc effect on locomotor activity, repeated administration of amphetamine directly into the VTA results in sensitized locomotor responses to subsequent systemic injections of amphetamine (Kalivas and Weber, 1988; Vezina and Stewart, 1990). However, because autoreceptor subsensitivity is a transient alteration that does not persist during withdrawal from repeated amphetamine treatment (White and Wang, 1984b; Wolf et al., 1993), it is clear that this alteration cannot account for the enduring nature of sensitization. Interestingly, a recent microdialysis study demonstrated that basal extracellular DA levels in the VTA are transiently increased following withdrawal from repeated cocaine treatment; this may be one functional consequence of VTA autoreceptor subsensitivity (Kalivas and Duffy, 1993b).

The expression of sensitization, and its persistence, may be related to changes occuring in the NAc, such as enhanced DA release or postsynaptic $\mathrm{D} \Lambda$ receptor supersensitivity. A role for the NAc in the expression of sensitization is consistent with the facts that acute intra-accumbens amphetamine injection will stimulate locomotor activity (Jackson et al., 1975; Pijnenburg et al., 1976) and, following repeated systemic amphetamine administration, an intra-accumbens challenge injection of amphetamine will elicit sensitized behavioral responses (Paulson and Robinson, 1991). Repeated injection of amphetamine into the NAc does not, however, lead to sensitization, arguing against a role for the NAc in its initiation (Dougherty and Fllinwood, 1981; Kalivas and Weber, 1988).

These findings suggest that the NAc is involved in the expression of behavioral sensitization. This hypothesis is supported by the fact that the time course of $D_{1}$ receptor supersensitivity, an alteration occuring in the NAc, mirrors that of behavioral sensitization. In the present study, $D_{1}$ receptor su- 
persensitivity was present following a $1 \mathrm{~d}$ withdrawal period and persisted for at least a week. In previous studies in cocainesensitized rats, $D_{1}$ receptor supersensitivity persisted for 1 month, as did sensitization, but was attenuated by 2 months, as was sensitization (Henry and White, 1991, and unpublished observations). The fact that coadministration of MK-801 prevents the development of $D_{1}$ receptor supersensitivity supports the idea that this alteration participates in the expression of sensitized behaviors.

Several findings suggest that VTA autoreceptor subsensitivity and postsynaptic $D_{1}$ receptor supersensitivity may be related steps in a chain of events leading to the sensitized state. First, both depend on NMDA receptor stimulation for their development, suggesting they may share a common initiating event. Second, previous studies have suggested that autoreceptor subsensitivity must occur, albeit transiently, in order for $D_{1}$ receptor supersensitivity to show persistence. Thus, repeated administration of cocaine, which produces a transient subsensitivity of $D_{2}$ autoreceptors, also results in long-lasting $D_{1}$ receptor supersensitivity in the NAc (Ackerman and White, 1990; Henry and White, 1991). In contrast, repeated treatment with the $D_{1}$ agonist SKF 38393 fails to influence VTA autoreceptor sensitivity and produces only a transient increase in $D_{1}$ sensitivity in the NAc (White et al., 1990; Hu et al., 1992). These results suggest that autoreceptor subsensitivity, perhaps via increases in DA cell firing rate, may lead to other, more persistent, alterations within the mesoaccumbens DA system such as $D_{1}$ receptor supersensitivity (or augmentation of DA release; see below). This would be in keeping with the fact that autoreceptor subsensitivity itself is unlikely to account for sensitization given that amphetamine-stimulated DA release has been shown to be largely independent of impulse flow in DA neurons (Kuczenski et al., 1990).

Another functional change that has been suggested to account for the persistence of hehavioral sensitization is an enhancement of the ability of amphetamine, as well as other releasing stimuli, to increase DA release in the striatum or NAc of sensitized rats or tissue slices prepared from sensitized rats (Robinson and Becker, 1982, 1986; Robinson et al., 1988). A number of reports, however, have suggested that augmentation of stimulated DA release can be dissociated from the expression of behavioral sensitization. In many studies examining DA release in dorsal or ventral striatum, augmentation of DA release has been reported to be absent after short withdrawals ( $1-3 \mathrm{~d})$ from repeated treatment with amphetamine or cocaine but to develop after longer withdrawals ( 1 week or greater), even though behavioral sensitization can be demonstrated at both short and long withdrawals. This pattern has been reported in studies examining DA release from striatal slices (Kuczenski and Leith, 1981; Kolta et al., 1985; Peris et al., 1990) as well as in microdialysis studies (Kalivas and Duffy, 1993a; Wolf et al., 1993). These results are consistent with those obtained by Robinson and coworkers, who have always examined amphetamine-stimulated DA release after withdrawals of at least $7 \mathrm{~d}$ (Robinson and Becker, 1982; Wilcox et al., 1986; Castaneda et al., 1988; Robinson et al., 1988).

In the present study, however, we failed to observe augmentation of DA release in sensitized rats after a $7 \mathrm{~d}$ withdrawal period. A previous study, using a treatment regimen $(2.5-3 \mathrm{mg} /$ $\mathrm{kg}$ amphetamine free base for 4-6 d, 2-6 d off) resembling that used in the present study, reported that behavioral sensitization was accompanied by a slight decrease in amphetamine-stimu- lated DA levels in both the caudate nucleus and NAc of awakc rats (Segal and Kuczenski, 1992a). Similar findings have been reported for cocaine-sensitized rats (Segal and Kuczenski, 1992b). It seems likely that the ability to demonstrate augmented DA release in sensitized rats is a function of variables relating to the drug treatment schedule (Kalivas and Stewart, 1991). Augmentation of DA release, like autoreceptor subsensitivity and postsynaptic DA receptor supersensitivity, may be only one link in a cascade of sequential changes important to the maintenance of a behaviorally sensitized state and may therefore be detectable only under certain conditions. Nevertheless, the present findings, which show that rats can exhibit markedly different locomotor responses to amphetamine challenge with no detectable difference in amphetamine-stimulated DA levels, establish a clear dissociation between augmented behavioral responses and augmented DA release in the NAc.

It is interesting to speculate about possible anatomical locations for the NMDA receptors involved in behavioral sensitization. NMDA (as well as non-NMDA) agonists are known to modulate DA cell activity at the level of the VTA and substantia nigra (Kalivas et al., 1989; Seutin et al., 1990; Charlety et al., 1991; Mereu et al., 1991; Johnson et al., 1992; Overton and Clark, 1992; Suaud-Chagny et al., 1992). It is possible that changes in excitalory amino acid transmission in the VTA during the course of repeated amphetamine treatment result in altered excitability of DA cells, which in turn leads to other events underlying sensitized behavioral responses. For example, enhanced excitatory tone on VTA DA cells might account for apparent DA autoreceptor subsensitivity (present findings) and enhanced basal activity of VTA DA neurons (White and Wang, 1984b), as well as for transient increases in basal and cocainestimulated DA release in the VTA following short withdrawals from cocaine treatment (Kalivas and Duffy, 1993b).

NMDA receptors in the forebrain can also exert indirect regulatory effects on VTA DA cells through long-loop feedback pathways. Thus, Zhang et al. (1992) have shown that systemic administration of MK-801 increases the firing rate of $A 9$ and A10 DA cells and regularizes their firing pattern. A role for descending forebrain glutamatergic projections in these effects was suggested by the fact that both effects were prevented by acute hemitransection at the level of the anterior half of the subthalamic nucleus. Descending excitatory afferents to the midbrain arise primarily from the subthalamic nucleus and the medial prefrontal cortex, while an ascending excitatory projection originates in the pedunculopontine nucleus (see Zhang et al., 1992, and references therein).

The NAc also receives excitatory inputs that could participate in sensitization. The hippocampus and amygdala provide the major monosynaptic excitatory inputs to the NAc and each of these systems appears to innervate medium spiny output neurons (Totterdell and Smith, 1989; Kita and Kitai, 1990; Sesack and Pickel, 1990). Medial prefrontal cortex, in addition to sending excitatory projections to the VTA, also projects to medium spiny neurons in the NAc (Sesack and Pickel, 1992). Several types of interactions between DA and excitatory amino acid transmission may occur in the NAc. Ultrastructural studies have demonstrated convergence of dopaminergic terminals and excitatory terminals originating from hippocampus or cortex on spines or dendrites of medium spiny neurons in striatum and NAc, consistent with hippocampal or cortical excitation (asymmetric junctions) and dopaminergic inhibition (symmetric junctions) of certain common medium spiny neurons (Bouyer et al., 
1984; Totterdell and Smith, 1989; Sesack and Pickel, 1990, 1992; see Smith and Bolam, 1990, for review). While these findings suggest opposing actions at the level of the striatal complex, studies on transmitter release from slices or synaptosomes suggest that glutamate agonists may enhance DA release (for recent references, see Clow and Jhamandas, 1989; Ascencio et al., 1991; Johnson and Jeng, 1991; Wang, 1991; Desce et al., 1992) while DA may exert inhibitory cffects on glutamate release (Maura et al., 1988, and references therein). Close appositions, but not axoaxonic synapses, have been noted between DA terminals and excitatory terminals originating from cortex or hippocampus (Bouyer et al., 1984; Sesack and Pickel, 1990). These appositions might account for presynaptic modulatory interactions between the two transmitters, although some effects may be attributable to interneurons (Peris et al., 1988).

The importance of the NAc in mediating both the acute and sensitized locomotor stimulatory effects of amphetamine, combined with the obvious potential for DA/excitatory amino acid interactions at the level of the NAc, supports the possibility that alterations in NMDA transmission in the NAc might participate in sensitization. On a cellular level, a change in excitatory tone on medium spiny cells might alter the responsiveness of these cells to dopaminergic inputs, resulting in apparent supersensitivity of $D_{1}$ responses. This would be consistent with the fact that functional $D_{1}$ supersensitivity following repeated cocaine administration cannot be accounted for by increased $D_{1}$ receptor number or enhanced simulation of DA-sensitive adenylate cyclase (Mayfield et al., 1992). It should be noted, however, that physiological interactions between DA and glutamate at the level of the striatal complex may be extremely complicated and may depend on many factors, including the level of tonic activity at dopaminergic and glutamatergic synapses. For example, tetanic stimulation of corticostriatal glutamatergic fibers in coronal slices containing both cortex and striatum has been reported to produce a long-term synaptic depression that requires coactivation of $D_{1}$ and $D_{2}$ receptors as well as activation of metabotropic glutamate receptors for its expression (Calabresi et al., 1992).

Finally, it should be noted that glutamate receptors throughout the basal ganglia may participate in the regulation of locomotor activity (see Carlsson and Carlsson, 1990, for review), suggesting that changes in NMDA transmission relevant to sensitization need not be limited to the VTA or NAc. The ubiquity of glutamate receptors in the motor circuitry, combined with the fact that alterations in activity at glutamatergic synapses can lead to both enhanced and attenuated transmission, that is, longterm potentiation or long-term depression, makes it very difficult to hypothesize about the mechanism through which NMDA and DA transmission might interact to generate sensitized locomotor responses. Indeed, the present results fall short of demonstrating a causal link between NMDA receptor stimulation, enhanced mesoaccumbens DA transmission, and the development of behavioral sensitization, and it remains possible that changes in mesoaccumbens DA function represent epiphenomena. It seems more likely, however, that these changes in DA function are links in a complicated series of neuronal changes, involving multiple neurotransmitter systems, which must occur in order for sensitization to be expressed (see White and Wolf, 1991, for further discussion). It will be interesting to explore possible alterations in excitatory amino acid transmission that may accompany the repeated administration of psychomotor stimulants.

\section{References}

Ackerman JM, White FJ (1990) A10 somatodendritic dopamine autoreceptor sensitivity following withdrawal from repeated cocaine treatment. Neurosci Lett 117:181-187.

Ascencio H, Bustos G, Gysling K, Labarca R (1991) N-methyl-Daspartate receptors and release of newly-synthesized $\left[{ }^{3} \mathrm{H}\right]$ dopamine in NAc slices and its relationship with neocortical afferents. Prog Neuropsychopharmacol Biol Psychiatry 15:663-676.

Benveniste H, Hansen AJ, Ottosen NS (1989) Detcrmination of brain interstitial concentrations by microdialysis. J Neurochem 52:17411750.

Bouyer JJ, Park DH, Joh TH, Pickel VM (1984) Chemical and structural analysis of the relation between cortical inputs and tyrosine hydroxylase-containing terminals in rat neostriatum. Brain Res 302: 267-275.

Bunney BS, Walters JR, Roth RH, Aghajanian GK (1973) Dopaminergic neurons: effect of antipsychotic drugs and amphetamine on single cell activity. J Pharmacol Exp Ther 185:560-571.

Calabresi P, Maj R, Pisani A, Mercuri NB, Bernardi G (1992) Longterm synaptic depression in the striatum: physiological and pharmacological characterization. J Neurosci 12:4224-4233.

Carlsson M, Carlsson A (1990) Interactions between glutamatergic and monoamincrgic systems within the basal ganglia-implications for schizophrenia and Parkinson's disease. Trends Neurosci 13:272276.

Castaneda E, Becker JB, Robinson TE (1988) The long-term effects of repeated amphetamine treatment in vivo on amphetamine, $\mathrm{KCl}$ and electrical stimulation evoked striatal dopamine release in vitro. Life Sci 42:2447-2456.

Charlety PJ, Grenhoff J, Chergui K, De La Chapelle B, Buda M, Svensson TH, Chouvet $G$ (1991) Burst firing of mesencephalic dopamine neurons is inhibited by somatodendritic application of kynurenate. Acta Physiol Scand 142:105-112.

Clow DW, Jhamandas K (1989) Characterization of L-glutamate action on the release of endogenous dopamine from the rat caudateputamen. J Pharmacol Exp Ther 248:722-728.

Creese I, Iverson SD (1974) The rolc of forcbrain dopaminc systcms in amphetamine induced stereotyped behavior in the rat. Psychopharmacology 39:345-357.

Desce JM, Godeheu G, Galli T, Artaud F, Cheramy A, Glowinski J (1992) L-Glutamate-evoked release of dopamine from synaptosomes of the rat striatum: involvement of AMPA and $N$-methyl-D-aspartate receptors. Neuroscience 47:333-339.

Dougherty GG Jr, Ellinwood EH Jr (1981) Chronic d-amphetamine in nucleus accumbens: lack of tolerance or reverse tolerance of locomotor activity. Life Sci 28:2295-2298.

Henry DJ, White FJ (1991) Repeated cocaine administration causes persistent enhancement of D1 dopamine receptor sensitivity within the rat nucleus accumbens. J Pharmacol Exp Ther 258:882-890.

Henry DJ, Greene MA, White FJ (1989) Electrophysiological effects of cocaine in the mesoaccumbens dopamine system: repeated administration. J Pharmacol Exp Ther 251:833-839.

Higashi H, Inanaga K, Nishi S, Uchimura N (1989) Enhancement of dopamine actions on rat nucleus accumbens neurones in vitro after methamphetamine pre-treatment. J Physiol (Lond) 408:587-603.

Hu X-T, Brooderson RJ, White FJ (1992) Repeated stimulation of D1 dopamine receptors causes time-dependent alterations in the sensitivity of both D1 and D2 dopamine receptors within the rat striatum. Neuroscience 50:137-147.

Jackson DM, Andén N-E, Dahlström A (1975) A functional effect of dopamine in the nucleus accumbens and in some other dopaminerich parts of the rat brain. Psychopharmacology 45:139-149.

Jeziorski M, White FJ, Wolf ME (in press) MK-801 prevents the development of behavioral sensitization during repeated morphine administration. Synapse, in press.

Johnson KM, Jeng Y-J (1991) Pharmacological evidence for $N$-methyl-D-aspartate receptors on nigrostriatal dopaminergic nerve terminals. Can J Physiol Pharmacol 69:1416-1421.

Johnson SW, Seutin V, North RA (1992) Burst firing in dopamine neurons induced by $N$-methyl-D-aspartate: role of electrogenic sodium pump. Science 258:665-667.

Kalivas PW, Weber B (1988) Amphetamine injection into the ventral mesencephalon sensitizes rats to peripheral amphetamine and cocaine. J Pharmacol Exp Ther 245:1095-1102.

Kalivas PW, Duffy P (1990) Effects of acute and daily cocaine treat- 
ment on extracellular dopamine in the nucleus accumbens. Synapse $5: 48-58$.

Kalivas PW, Duffy P (1993a) Time course of extracellular dopamine and behavioral sensitization to cocaine. I. Dopamine axon terminals. J Neurosci 13:266-275.

Kalivas PW, Duffy P (1993b) Time course of extracellular dopamine and behavioral sensitization to cocaine. II. Dopamine perikarya. J Neurosci 13:276-284

Kalivas PW, Stewart J (1991) Dopamine transmission in the initiation and expression of drug- and stress-induced sensitization of motor activity. Brain Res Rev 16:223-244.

Kalivas PW, Duffy P, Barrow J (1989) Regulation of the mesocorticolimbic dopamine system by glutamic acid receptor subtypes. J Pharmacol Exp Ther 251:378-387.

Kamata K, Rebec GV (1984) Long-term amphetamine treatment attenuates or reverses the depression of neuronal activity produced by dopamine agonists in the ventral tegmental area. Life Sci 34:24192427.

Karler R, Calder LD, Chaudhry IA, Turkanis SA (1989) Blockade of 'reverse tolerance' to cocaine and amphetamine by MK-801. Life Sci 45:599-606

Karler R, Chaudhry IA, Calder LD, Turkanis SA (1990) Amphetamine behavioral sensitization and the excitatory amino acids. Brain Res 537:76-82.

Karler R, Calder LD, Turkanis SA (1991) DNQX blockade of amphctamine bchavioral sensitization. Brain Res 552:295--300.

Kita H, Kitai ST (1990) Amygdaloid projections to the frontal cortex and the striatum in the rat. J Comp Neurol 298:40-49.

Kolta MG, Shreve P, De Souza V, Uretsky NJ (1985) Tine course of the development of the enhanced behavioral and biochemical responses to amphetamine after pretreatment with amphetamine. Neuropharmacology 24:823-829

Kuczenski R, Leith NJ (1981) Chronic amphetamine: is dopamine a link in or a mediator of the development of tolerance and reverse tolerance? Pharmacol Biochem Behav 15:405-413.

Kuczenski R, Segal DS, Manley LD (1990) Apomorphine does not alter amphetamine-induced dopamine release measured in striatal dialysates. J Neurochem 54:1492-1499.

Maura G, Giardi A, Raiteri M (1988) Release-regulating D-2 dopamine receptors are located on striatal glutamatergic nerve terminals. J Pharmacol Exp Ther 247:680-684.

Mayfield RD, Larson G, Zahniser NR (1992) Cocaine-induced behavioral sensitization and $\mathrm{D}_{1}$ dopamine receptor function in rat nucleus accumbens and striatum. Brain Res 573:331-335.

Mereu G, Costa E, Armstrong DM, Vicini S (1991) Glutamate receptor subtypes mediate excitatory synaptic currents of dopamine neurons in midbrain slices. J Neurosci 11:1359-1366.

Overton P, Clark D (1992) Iontophoretically administered drugs acting at the $N$-methyl-D-aspartate receptor modulate burst firing in A9 dopamine neurons in the rat. Synapse 10:131-140.

Paulson PF, Robinson TF (1991) Sensitization to systemic amphetamine produces an enhanced locomotor response to a subsequent intra-accumbens amphetamine challenge in rats. Psychopharmacology 104:140-141.

Paxinos G, Watson C (1986) The rat brain in stereotaxic coordinates. New York: Academic.

Peris J, Dwoskin LP, Zahniser NR - (1988) Biphasic modulation of evoked $\left[{ }^{3} \mathrm{H}\right] \mathrm{D}$-aspartate release by $\mathrm{D}-2$ dopamine receptors in rat striatal slices. Synapse 2:450-456.

Peris J, Boyson SJ, Cass WA, Curella P, Dwoskin LP, Larson G, Lin L-H, Yasuda RP, Zahniser NR (1990) Persistence of neurochemical changes in dopamine systems after repeated cocaine administration. J Pharmacol Exp Ther 253:38-44.

Pettit HO, Pan H-T, Parsons LH, Justice JB Jr (1990) Extracellular concentrations of cocaine and dopamine are enhanced during chronic cocaine administration. J Neurochem 55:798-804.

Pijnenburg AJJ, Honig WMM, van der Heyden JAM, van Rossum JM (1976) Effects of chemical stimulation of the mesolimbic dopamine system upon locomotor activity. Eur J Pharmacol 35:45-58.

Robinson TE, Becker JB (1982) Behavioral sensitization is accompanied by an enhancement in amphetamine-stimulated dopamine release from striatal tissue in vitro. Eur J Pharmacol 85:253-254.

Robinson TE, Becker JB (1986) Enduring changes in brain and behavior produced by chronic amphetamine administration: a review and evaluation of animal models of amphetamine psychosis. Brain Res Rev 11:157-198.
Robinson TE, Whishaw IQ (1988) Normalization of extracellular dopamine in striatum following recovery from a partial unilateral 6-OHDA lesion of the substantia nigra: a microdialysis study in freely moving rats. Brain Res 450:209-224.

Robinson TE, Jurson PA, Bennett JA, Bentgen KM (1988) Persistent sensitization of dopamine neurotransmission in ventral striatum (nucleus accumbens) produced by prior experience with $(+)$-amphetamine: a microdialysis study in freely moving rats. Brain Res 462 $211-222$

Segal DS, Kuczenski R (1992a) In vivo microdialysis reveals a diminished amphetamine-induced DA response corresponding to behavioral sensitization produced by repeated amphetamine treatment. Brain Res 571:330-337.

Segal DS, Kuczenski R (1992b) Repeated cocaine administration induces behavioral sensitization and corresponding decreased extracellular dopamine responses in caudate and accumbens. Brain Res 577:351-355.

Sesack SR, Pickel VM (1990) In the rat medial nucleus accumbens, hippocampal and catecholaminergic terminals converge on spiny neurons and are in apposition to each other. Brain Res 527:266-279.

Sesack SR, Pickel VM (1992) Prefrontal cortical efferents in the rat synapse on unlabeled neuronal targets of catecholamine terminals in the nucleus accumbens septi and on dopamine neurons in the ventral tegmental area. J Comp Neurol 320:145-160.

Seutin V, Verbanck P, Massotte L, Dresse A (1990) Evidence for the presence of $N$-methyl-D-aspartate receptors in the ventral tegmental area of the rat: an electrophysiological in vitro study. Brain Res 514: $147-150$

Sharp T, Zetterströn T, Ljungberg T, Ungerstedt U (1987) A direct comparison of amphetamine-induced behaviours and regional brain dopamine release in the rat using intracerebral dialysis. Brain Res $401: 322-330$

Smith AD, Bolam JP (1990) The neural network of the basal ganglia as revealed by the study of synaptic connections of identified neurones. Trends Neurosci 13:259-265.

Suaud-Chagny MF, Chergui K, Chouvet G, Gonon F (1992) Relationship between dopamine release in the rat nucleus accumbens and the discharge activity of dopaminergic neurons during local in vivo application of amino acids in the ventral tegmental area. Neuroscience 49:63-72.

Totterdell S, Smith AD (1989) Convergence of hippocampal and dopaminergic input to identified neurons in the nucleus accumbens of the rat. J Chem Neuroanat 2:285-298.

Vezina P (1993) Amphetamine injected into the ventral tegmental area sensitizes the nucleus accumbens dopaminergic response to systemic amphetamine: an in vivo microdialysis study in the rat. Brain Res 605:332-337

Vezina P, Stewart J (1990) Amphetamine administered to the ventral tegmental area but not to the nucleus accumbens sensitizes rats to systemic morphine: lack of conditioned effects. Brain Res 516:99106

Wang JKT (1991) Presynaptic glutamate receptors modulate dopamine release from striatal synaptosomes. J Neurochem 57:819-822.

Wang RY (1981) Dopaminergic neurons in the rat ventral tegmental area. I. Identification and characterization. Brain Res Rev 3:123-140.

White FI, Wang RY (1984a) A10 dopamine neurons: role of autoreceptors in determining firing rate and sensitivity to dopamine agonists. Life Sci 34:1161-1170.

White FJ, Wang RY (1984b) Electrophysiological evidence for A10 dopamine autoreceptor subsensitivity following chronic D-amphetamine treatment. Brain Res 309:283-292.

White FJ, Wang RY (1984c) Pharmacological characterization of dopamine autoreceptors in the rat ventral tegmental area: microiontophoretic studies. J Pharmacol Exp ther 231:275-280.

White FJ, Wolf ME (1991) Psychomotor stimulants. In: The biological basis of drug tolerance and dependence (Pratt JA, ed), pp 153-197. London: Academic.

White FJ, Hu X-T, Brooderson RJ (1990) Repeated stimulation of Dl dopamine receptors enhances the effects of DA agonists. Eur $\mathbf{J}$ Pharmacol 191:497-499.

Wilcox RA, Robinson TE, Becker JB (1986) Enduring enhancement in amphetamine-stimulated striatal dopamine release in vitro produced by prior exposure to amphetamine or stress in vivo. Eur $\mathbf{J}$ Pharmacol 124:375-376.

Wolf ME, Jeziorski M (1993) Coadministration of MK-801 with amphetamine, cocaine or morphine prevents rather than transiently masks 
the development of behavioral sensitization. Brain Res 613:291-294.

Wolf ME, Khansa MR (1991) Repeated administration of MK-801 produces sensitization to its own locomotor stimulant effects but blocks sensitization to amphetamine. Brain Res 562:164-168.

Wolf ME, White FJ, Nassar R, Brooderson RJ, Khansa MR (1993)

Differential development of autoreceptor subsensitivity and enhanced dopamine release during amphetamine sensitization. J Pharmacol Exp Ther 264:249-255.

Zhang J, Chiodo LA, Freeman AS (1992) Electrophysiological effects of MK-801 on rat nigrostriatal and mesoaccumbal dopaminergic neurons. Brain Res 590:153-163. 